\title{
Eating soup with nails of pig: thematic synthesis of the qualitative literature on cultural practices and beliefs influencing perinatal nutrition in low and middle income countries
}

\author{
Shanti Raman ${ }^{1 *}$, Rachel Nicholls ${ }^{2}$, Jan Ritchie ${ }^{3}$, Husna Razee ${ }^{3}$ and Samaneh Shafiee ${ }^{3}$
}

\begin{abstract}
Background: The perinatal period, i.e. pregnancy, childbirth and early infancy, is a significant transition period where the biological and the social strongly intersect. In low and middle-income countries the disease burden arising from the perinatal period, is still substantial. The perinatal period is also a crucial window of opportunity for reducing undernutrition and its long term adverse effects.

Methods: We explored qualitative research conducted in low resource settings around the perinatal continuum over the past two decades, with a particular focus on the 'cultural' realm, to identify common themes influencing maternal and infant nutrition. We systematically searched electronic databases from 1990 to 2014, including MEDLINE, EMBASE, PsycINFO, Scopus and Cumulative Index to Nursing and Allied Health Literature, using relevant search terms including traditional beliefs, practices, pregnancy, childbirth, developing countries etc. Adapted Consolidated Criteria for Reporting Qualitative Health Research and Critical Appraisal Skills Programme criteria were used to determine quality of studies. We synthesised the literature thematically, enabled by NVivo 10 software.

Results: Most studies showed cultural support for breastfeeding, although most traditional societies delayed breastfeeding due to colostrum being considered 'dirty'. A range of restrictive practices through pregnancy and the post- partum period were revealed in Asia, Latin America and Africa. There was a strong cultural understanding of the healing power of everyday foods. A wide range of good foods and bad foods continued to have currency through the perinatal continuum, with little consensus between groups of what was beneficial versus harmful. Cross-cutting themes that emerged were 1) the role of the woman/mother/wife as strong and good; 2) poverty restricting women's nutrition choices; 3) change being constant, but the direction of change unpredictable. (Continued on next page)
\end{abstract}

\footnotetext{
* Correspondence: s.raman@unsw.edu.au

${ }^{1}$ School of Public Health \& Community Medicine, University of New South Wales, \& South Western Sydney Local Health District, Health Services Building Level 3, Cnr Campbell \& Goulburn St, Liverpool, NSW 2170, Australia

Full list of author information is available at the end of the article
} 
(Continued from previous page)

Conclusions: A rich and diverse repertoire of cultural practices and beliefs influenced perinatal nutrition. Results from this synthesis should influence public health policymakers and practitioners, to tailor contextually specific, culturally responsive perinatal nutrition interventions to optimise health and wellbeing of mother-infant dyads. Ideally these interventions should build on culturally sanctioned life affirming behaviours such as breastfeeding, promoting post-partum rest and recovery, while modifying the potentially harmful aspects of other cultural practices in the perinatal period.

Keywords: Maternal health, Low and middle-income countries, Maternal and child nutrition, Breastfeeding, Culture, Traditional practices, Qualitative research, Synthesis

\section{Background}

Health conditions affecting the perinatal period account for a major contribution to disease burden in sub-Saharan Africa and South Asia [1, 2], making the perinatal period a key period for health intervention. Despite this understanding there remain major gaps and disparities, with the burden of maternal and child mortality, morbidity and malnutrition occurring largely in resource poor settings. Many international studies have highlighted the importance of maternal factors such as education levels, health, and nutrition in infant and child outcomes [3-5], upstream social determinants such as poverty, illiteracy, poor status and care of women are also known critical underlying factors $[6,7]$. A major review of what "works" in maternal and child health in the developing world found a paucity of good quality community-based data from developing-country studies [8].

In the post millennium development goal (MDG) era, maternal and child undernutrition continue to be problematic contributing to 800000 neonatal deaths, stunting, wasting, micronutrient deficiencies, and nearly three million child deaths annually [9]. There are significant barriers at the household level in accessing appropriate nutrition for women and children [10]. The period from in-utero to 24 months of age, i.e. the perinatal period, is a crucial window of opportunity for reducing undernutrition and its adverse effects [11]. While pregnancy and childbirth are natural health transitions; biophysical, psychosocial, cultural, and social factors are integral to the perinatal experience and impact on outcomes. There is robust evidence from diverse settings that health care seeking [12, 13], maternal [14], and child survival [15] can be influenced by socio-cultural factors.

There is an emerging body of research that illuminates the ways in which maternal dietary and infant feeding practices relate substantially to local cultural norms and constraints $[10,16,17]$. We therefore aimed to explore qualitative research conducted in low resource settings around the perinatal continuum, with a particular focus on the 'cultural' realm of shared beliefs, values, and practice; and to identify common themes in the research-base. Our understanding of culture was deliberately broad and drew upon both "transmitted pattern of meanings embodied in symbols, a system of inherited conceptions expressed in symbolic form" [18], and "complex integrated system of thought and behaviour shared by members of a group" [19]. We focused on the period 1990 to 2014, incorporating the years of accountability of the MDGs, to explore change in cultural practices over the decades.

Given the established burden of maternal and child morbidity and mortality in low resource settings, this review focused on published qualitative studies from low and middle-income countries (LMICs) that explored cultural beliefs and practices influencing perinatal nutrition for mother and infant. The review is part of a larger synthesis exploring wider cultural practices and beliefs influencing perinatal health and wellbeing.

\section{Methods}

We chose to limit our review and synthesis to qualitative research as we were focusing on cultural beliefs, practices; and wanted to mine rich primary data. Interpretive synthesis of qualitative research is a distinct methodology with distinct benefits, offering the potential for insight, vividness and significantly inform policy and practice $[20,21]$. We sought studies presenting primary data and involving purely qualitative or mixed method data collection techniques (interviews, focus groups, ethnography) reporting on cultural or traditional practices and beliefs influencing the perinatal period (i.e. pregnancy, childbirth and infancy) in LMICs. We excluded studies from countries not classified by the World Bank as LMIC [22]. We also excluded articles which had no information on cultural practices/beliefs, had no qualitative data, or no primary data; those specifically focussed on high risk conditions such as Human immune-deficiency virus (HIV), diabetes, post-partum haemorrhage, perinatal loss and anaemia. Non-English articles were excluded to prevent cultural and linguistic bias in translations.

We systematically searched the following electronic databases from 1990 to 2014: MEDLINE, EMBASE, Cochrane Library, PsycINFO, Cumulative Index to Nursing and Allied Health Literature (CINAHL), Science 
Citation Index, WHO Global Health Library, Scopus, Web of Science and reference lists of relevant articles. An example of the search strategy used for electronic databases including MEDLINE and EMBASE was: (perinatal OR pregnancy OR childbirth OR antenatal OR postnatal OR infancy) AND ("traditional beliefs" OR "cultural beliefs" OR "cultural practices") AND ("developing countries" OR "low income" OR "low resource setting") AND (qualitative OR "focus group" OR interviews OR ethnography). We also searched Qualitative Health Research, Qualitative Research, Social Science and Medicine, Qualitative Inquiry and Google Scholar. Hand searching complemented electronic searches. Searches were conducted using the following individual and combined keywords: perinatal, pregnancy, childbirth, antenatal, postnatal, infancy, traditional beliefs, cultural beliefs, cultural practices, developing countries, low income, low resource setting. The search was conducted between 6 June to 12 August 2014, and followed the preferred reporting items for systematic reviews and meta-analyses (PRISMA) guidelines where applicable [23], see attached PRISMA checklist (Additional file 1).

Two reviewers (SR and RN) screened the abstracts, discarding studies that did not fit the inclusion criteria. The full-text versions of retrieved studies were analysed and examined for study eligibility with uncertainties and disagreements being resolved in consultation among the reviewers. Two authors (SR and RN) independently assessed the explicitness and comprehensiveness of reporting (i.e. quality of studies) by using an adapted consolidated criteria for reporting qualitative research framework (COREQ) [24], scored out of 12, and the CASP Qualitative Research Checklist [25], scored out of 10 .

We performed a synthesis of the studies that met the inclusion criteria, based on the J Thomas and A Harden [21] 'thematic synthesis' method, which draws on the principles of primary qualitative research. For each paper with primary data, i.e., from interviews, focus groups, ethnography, we extracted all the participant quotations and descriptive text under the "results/findings" or "conclusion/discussion" section of the article. These were entered verbatim into NVivo 10 [26]. Our process of thematic synthesis involved line-by-line coding of the findings of the primary studies, organizing the codes into descriptive themes, and abstracting the findings to produce a new interpretation, which went beyond the original studies [21].

\section{Results}

Our initial search revealed 273 papers. After 10 duplicates were removed, 263 remained, but 195 were excluded primarily because they did not report qualitative research. An additional eight articles were identified from hand searching. Of the 76 eligible studies, five were further excluded, leaving a final list of 71 (see Fig. 1). Table 1 lists studies by region, author, year published and quality scores. Most studies were from Africa and Asia and the majority were published after 2000 (Table 2).

The following themes relating to cultural practices and beliefs influencing perinatal nutrition were identified.

Breastfeeding: "Everyone here breastfeeds their babies" [27] Breastfeeding was overwhelmingly supported culturally, but there was wide variation in practice. Several cultural practices supported breastfeeding, including "preparing the breast and cleaning both mother and infant" [27], and massaging fire ash around the breast when wet [28], as in rural Laos. On the other hand, taboos and prohibitions pertaining to breastfeeding were also common. While religious support for breastfeeding was apparently valued, "the ideal breastfeeding duration is up to two years according to Islam" (Pakistani woman) [29], a young Turkish mother had different understanding [30]:

Pregnant women's milk is spoiled milk. It may give harm to the breastfed baby.. . . I know it because the Imam [Muslim priest] said pregnant women should not breastfeed their babies.

Prelacteal feeds were particularly common in South Asia and were believed to have healing and religious properties. Whether in rural India "hot water, sugarwater, honey, mustard oil, tea, or goat/cow milk" [31], or "sugar water (misri pani) and banana" in Bangladesh [32] or 'Ghutti' (honey, butter mixed with sugar, glucose and other liquids) across northern India and Pakistan [29]. In Pakistan for example mothers will not breastfeed till an elderly pious person gives the baby ghutti; believed to transfer their qualities to the baby [33]. In Uganda, younger mothers tended to "give glucose", whereas older mothers tended to give "water, sugar, salt or tea" [34].

Beliefs about maternal behaviour influencing the quality of breast milk are illustrated in this quote from elderly women in rural Nigeria, "in the past, a breastfeeding mother could not sleep with her husband because it would cause diarrhoea in her baby.. .but these days there are drugs everywhere" [35]. Prolonged breastfeeding while generally supported in traditional societies, can co-exist with abrupt weaning, as in the Tarok in Nigeria, who believe that pregnancy affects breastmilk making it unhealthy for the child [35]:

In a traditional setting, the child should be up to one year, eighteen months, or two years plus before you stop breastfeeding. When you stop before then it 


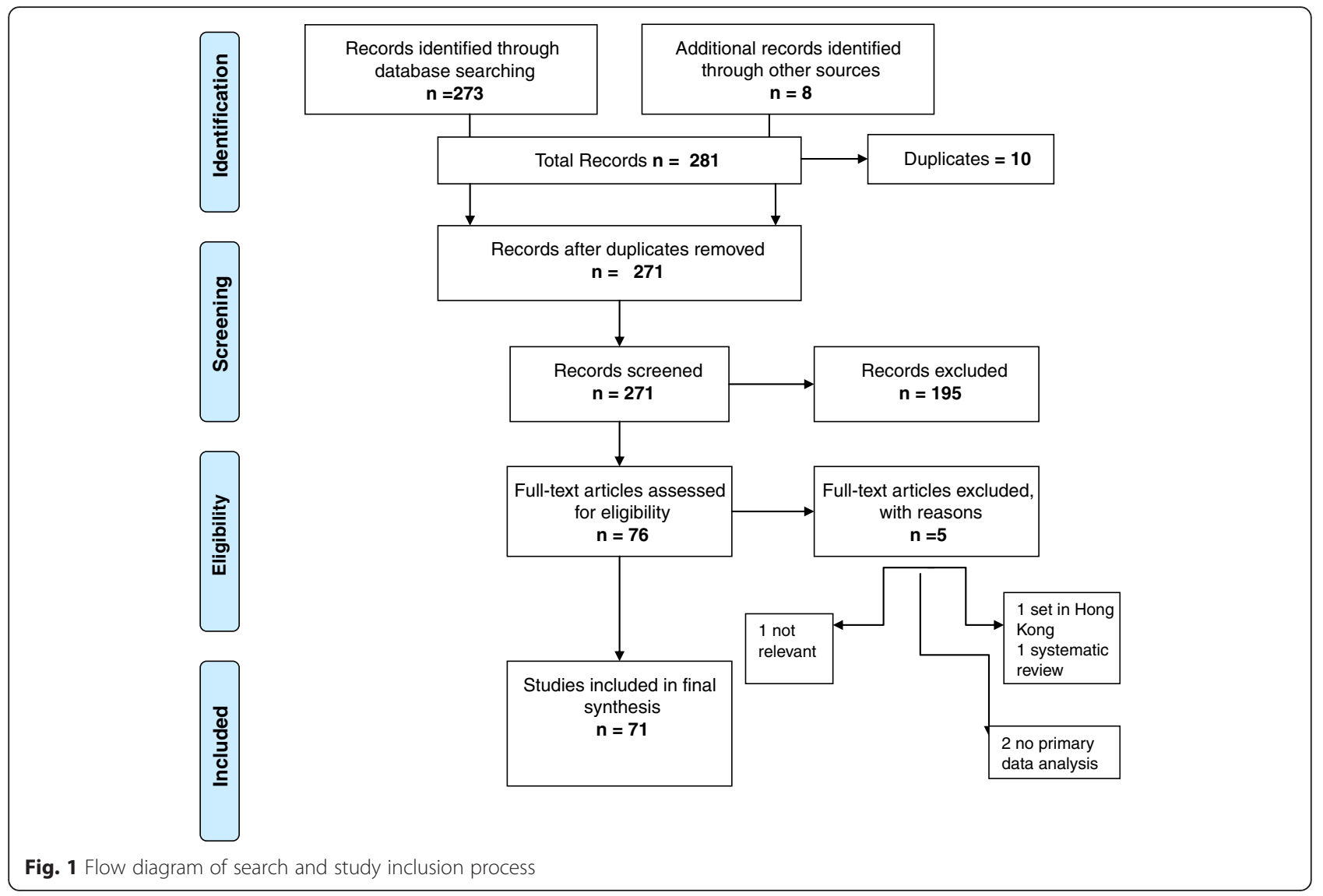

attracts a lot of stories in the community.. . that you want to spoil your child, you want to start sleeping with your husband, and so on." (Older Tarok woman)

Traditional practices to see if breastmilk is good enough may still be practised in parts of Africa; for example "an ant was placed in the milk and if the ant died, the milk was considered unwholesome" (Ghana) [36].

We found that colostrum was routinely rejected by most traditional societies, although change has been slowly occurring. Colostrum in Turkish dialect was referred to as mawu (new milk) or fro (dense milk); Turkish women believe that it should not be given to newborns as it caused "stomach ache" [30]. Indeed some women even felt "that colostrum can kill the baby because it is dense, dirty, old milk stored in the breast for 9 months" [33].

I put my son to breast after two days, as the milk 'comes' only after 48 hours. Before I put him to breast I squeezed the yellowish liquid and threw it, as it is harmful for his health. (mother from rural India) [31]

Breastfeeding was strongly sanctioned and supported by elders, "my mother was the first one who motivated me to breastfeed, she talked about breastfeeding before the doctor did" (young mother, Vientiane) [28]. However there were differences of opinion between elders and health professionals; elders advised discarding colostrum, delaying initiation of breastfeeding or introduction of other food well before six months [28, 37], whereas health professionals advocated exclusive breastfeeding for six months. Mothers revealed ambivalence about duration of breastfeeding; while breast milk was "best in the first period of birth", Laotian and other Asian mothers felt that that as the baby grows, breast milk contained insufficient nutrients [28].

\section{Healing foods and medicines: “God's own way of helping the baby" [38]}

There was widespread belief in the healing properties of certain foods and its use in the perinatal period; especially in more traditional populations in Asia and Africa (see Table 3). In Myanmar, "almost all women did smearing or drinking of turmeric to prevent muscle pain" [39]. Traditional medicines and herbal preparations for the puerperium and to strengthen breast milk were highly prevalent, to "help with expelling lochia and control post-partum bleeding" and to "produce breast milk abundantly." In Myanmar as in other parts of South 
Table 1 Included studies by region, author, year and quality scores

\begin{tabular}{|c|c|c|c|}
\hline Setting & Author (Year) & CASPa Score & COREQ $^{\text {b }}$ score \\
\hline \multicolumn{4}{|l|}{ Africa } \\
\hline Nigeria, rural & Asowa-Omorodion (1997) [74] & 7 & 8 \\
\hline Uganda, rural & Ayiasi et al. (2013) [34] & 8 & 10 \\
\hline Mozambique, peri urban & Chapman (2003) [75] & 9 & 9 \\
\hline Ghana, urban & Dako-Gyeke et al. (2013) [42] & 9 & 8 \\
\hline Ethiopia, rural & Degefie et al., (2014 ) [76] & 8 & 6 \\
\hline Burkina Faso, rural & Donmozoun et al. (2014) [77] & 6 & 4 \\
\hline Sierra Leone, rural \& urban & Dorwie and Pacquiao (2014) [78] & 10 & 10 \\
\hline Nigeria, rural \& urban & Ejidokun (2000) [55] & 10 & 10 \\
\hline Ghana, rural \& urban & Farnes et al. (2011) [38] & 10 & 10 \\
\hline Ethiopia, rural & Gebrehiwot et al. (2012) [79] & 9 & 7 \\
\hline Kenya, rural \& urban & Geissler et al. (1999) [45] & 7 & 6 \\
\hline Tanzania, rural & Gross et al. (2013) [80] & 8 & 10 \\
\hline Uganda, rural & Kwagala (2013) [57] & 9 & 6 \\
\hline Uganda, rural & Kyomuhendo (2003) [81] & 7 & 5 \\
\hline Liberia, rural & Lori and Boyle (2011) [82] & 10 & 11 \\
\hline Zambia, rural \& urban & Maimbolwa et al. (2003) [41] & 10 & 10 \\
\hline Tanzania, urban & Mbekenga et al. (2013) [72] & 9 & 9 \\
\hline Ghana, rural & Mills and Bertrand (2005) [36] & 9 & 10 \\
\hline Ghana, rural & Moyer et al. (2014) [13] & 9 & 10 \\
\hline S Africa, rural & Ngomane and Mulaudzi (2012) [83] & 9 & 9 \\
\hline Nigeria, rural & Orisaremi (2013) [35] & 9 & 7 \\
\hline S Africa, rural & Preez (2012) [84] & 8 & 10 \\
\hline Ghana, peri urban & Theroux et al. (2013) [58] & 7 & 11 \\
\hline Swaziland, rural & Thwala et al. (2011) [62] & 7 & 9 \\
\hline Swaziland, rural & Thwala et al. (2012) [85] & 8 & 10 \\
\hline Cameroon, rural & Thwala et al. (2012) [86] & 9 & 9 \\
\hline Ethiopia, rural \& urban & Warren (2010) [87] & 6 & 6 \\
\hline Ghana, rural & Wilkinson and Callister (2010) [61] & 9 & 8 \\
\hline Malawi, rural & Zulu (2001) [88] & 8 & 8 \\
\hline \multicolumn{4}{|l|}{ South Asia } \\
\hline Bangladesh, urban & Ahmed et al. (2010) [60] & 9 & 7 \\
\hline India, rural & Bandyopadhyay (2009) [31] & 7 & 9 \\
\hline Nepal, peri urban & Brunson (2010) [73] & 9 & 11 \\
\hline Bangladesh, rural & Choudhury and Ahmed (2011) [89] & 9 & 9 \\
\hline Bangladesh, urban & Choudhury et al. (2012) [54] & 8 & 8 \\
\hline Pakistan, rural & Dykes et al. (2012) [29] & 7 & 7 \\
\hline Pakistan, urban & Fikree et al. (2004) [51] & 8 & 4 \\
\hline Pakistan, urban & Fikree et al. (2005) [16] & 7 & 6 \\
\hline India, rural & lyengar et al. (2008) [90] & 8 & 8 \\
\hline Nepal, rural & Kaphle et al. (2013) [63] & 10 & 10 \\
\hline India, rural & Kesterton and Cleland (2009) [91] & 8 & 10 \\
\hline Pakistan, rural & Khadduri et al. (2008) [33] & 7 & 6 \\
\hline Bangladesh, urban & Moran et al. (2009) [92] & 9 & 8 \\
\hline
\end{tabular}


Table 1 Included studies by region, author, year and quality scores (Continued)

\begin{tabular}{|c|c|c|c|}
\hline Pakistan, rural & Premji et al. (2014) [37] & 10 & 11 \\
\hline Bangladesh, urban & Rashid (2007) [93] & 8 & 8 \\
\hline India, rural & Sharma et al. (2013) [94] & 10 & 10 \\
\hline Nepal, rural & Thapa et al. (2000) [52] & 7 & 6 \\
\hline Bangladesh, rural & Winch et al. (2005) [32] & 8 & 7 \\
\hline \multicolumn{4}{|l|}{ Asia, other } \\
\hline Tibet, rural & Adams et al. (2005) [43] & 10 & 9 \\
\hline Laos, rural & Alvesson et al. (2013) [95] & 9 & 8 \\
\hline Laos, rural & de Sa et al. (2013) [27] & 8 & 8 \\
\hline Turkey, urban & Ergenekon-Ozelci et al. (2006) [30] & 7 & 5 \\
\hline Vietnam, rural & Graner et al. (2013) [96] & 10 & 10 \\
\hline Philippines, peri urban & Hadwiger and Hadwiger (2012) [50] & 9 & 10 \\
\hline China, urban & Kartchner and Callister (2003) [97] & 9 & 8 \\
\hline Laos, urban & Lee et al. (2013) [28] & 10 & 9 \\
\hline Vietnam, urban & Lundberg and Ngoc Thu (2012) [46] & 9 & 11 \\
\hline Vietnam, urban & Lundberg and Trieu Thi Ngoc (2011) [49] & 10 & 11 \\
\hline Cambodia, rural & Matsuoka et al. (2010) [98] & 8 & 5 \\
\hline China, rural & Raven et al. (2007) [48] & 9 & 11 \\
\hline Myanmar, rural \& urban & Sein (2013) [39] & 10 & 8 \\
\hline China, rural & Strand et al. (2009) [53] & 9 & 7 \\
\hline Laos, rural & Sychareun et al. (2012) [99] & 8 & 10 \\
\hline Cambodia, rural & White (2002) [40] & 9 & 7 \\
\hline Cambodia, rural & White (2004) [47] & 9 & 8 \\
\hline Bali, rural & Wulandari and Klinken Whelan (2011) [44] & 9 & 10 \\
\hline \multicolumn{4}{|l|}{ Middle East } \\
\hline Syria, urban & Abushaikha and Massah (2013) [100] & 8 & 11 \\
\hline Jordan, urban & Khalaf and Callister (1997) [101] & 8 & 7 \\
\hline \multicolumn{4}{|l|}{ Latin America } \\
\hline Guatemala, rural & Berry (2006) [102] & 8 & 8 \\
\hline Argentina, urban & Hess and Maughan (2012) [59] & 8 & 6 \\
\hline Brazil, rural & Piperata (2008) [56] & 10 & 9 \\
\hline Guatemala, rural & Radoff et al. (2013) [103] & 10 & 8 \\
\hline
\end{tabular}

${ }^{a}$ CASP Critical Appraisal Skills Programme, scored out of 10

${ }^{b}$ COREQ consolidated criteria for reporting qualitative research, scored out of 12

East Asia, "licensed indigenous medicine" were available even in hospitals [39]. "If you have blood left inside, you feel weak, ... then you find Khmer medicine to drink to make all the blood come out.."; Cambodian women's perspectives [40]. In parts of Africa where home births were practised, traditional birth assistants' advice to women included the use of traditional medicines to widen the birth canal and precipitate labour. As this Zambian mbusa (traditional birth attendant) explained, "if the labour is prolonged and the woman has confessed that she has been unfaithful to her husband, she should be given traditional medicine so that labour can progress well!" [41].
In many traditional societies, ethno-medicine was an accepted part of the perinatal experience and herbs were prescribed by a range of religious and healthcare professionals, including herbalists, akomfo (witch doctor), Christian pastors and birth attendants. In many parts of Africa herbs promoted women's sense of autonomy and "can be considered God's medicine" [38], Ghanaian women reported that "herbal medicine gives strength", whereas hospital drugs "weakens me when I take them" [42]. Tibetan medical texts prescribed traditional food and drink as rituals for newborn care [43]. In Bali, traditional treatments were also common, according to this informant [44]: 
Table 2 Summary of included studies by region, time period and quality scores

\begin{tabular}{llllll}
\hline Region & $(\mathrm{N})$ & Time frame & $(\mathrm{N})$ & CASP $^{\mathrm{a}}$ Scores & COREQ $^{\mathrm{b}}$ scores \\
\hline Africa & 29 & $1990-1999$ & 2 & 7 & $6-8$ \\
& & $2000-2009$ & 6 & $7-10$ & $8-10$ \\
& & $>2010$ & 21 & $6-10$ & $4-11$ \\
South Asia & 18 & $2000-2009$ & 10 & $7-9$ & $6-9$ \\
& & $>2010$ & 8 & $8-10$ & $7-11$ \\
Asia (other) & 18 & $2000-2009$ & 7 & $7-10$ & $5-11$ \\
& & $>2010$ & 11 & $8-10$ & $5-11$ \\
Latin America & 4 & $2000-2009$ & 2 & $8-10$ & $8-9$ \\
& & $>2010$ & 2 & $8-10$ & $6-8$ \\
Middle East & 2 & $1990-1999$ & 1 & 8 & 7 \\
& & $>2010$ & 1 & 8 & 11
\end{tabular}

${ }^{a}$ CASP Critical Appraisal Skills Programme, scored out of 10

${ }^{\mathrm{b}} \mathrm{COREQ}$ consolidated criteria for reporting qualitative research, scored out of 12
Health-care workers are always thinking that it is medicine that will keep us healthy. The truth is there are many alternatives we can use to make us healthy. One of them is traditional herbs.

A practice reported widely in African studies was soil eating. Attitudes to soil-eating were ambivalent and gendered; women's soil-eating being more acceptable than men's and only really approved of for pregnant women [45]. Kenyan women believed that soil influences the volume and condition of the blood, which in turn affects the tsango (guardian of the body's health and fertility).

Good food versus bad food: "Eat soup with nails of pig or pork ragout and green papaya every week" [46]

The synthesis revealed a wide range of foods that were considered helpful or 'good' versus those that were actively harmful. Across Asia, notions of foods that were considered "heaty" as against those that were considered cooling had widespread currency. In many parts of Asia, post- partum cultural practices necessarily involve restoring heat to the woman's body; recognising that having lost energy and blood during delivery, both yin and yang are weakened. Khmer women ate special hot foods such as Khaw (a traditional dish of beef), pork, or fish

Table 3 Examples of ethno medicine / healing foods used by women during the perinatal period

\begin{tabular}{|c|c|c|c|}
\hline Author & Region & Food substances & Effect \\
\hline \multirow{2}{*}{$\begin{array}{l}\text { Adams } \\
{[43]}\end{array}$} & \multirow[t]{2}{*}{ Tibet } & Butter ingested by newborn & \multirow[t]{2}{*}{ In order for child to have a clear mind and well-developed senses } \\
\hline & & Chang warm barley beer ingested by mothers & \\
\hline Ayiasi [34] & Uganda & Waragi local alcohol & Generally therapeutic, keeps infant's skin clear \\
\hline $\begin{array}{l}\text { Farnes } \\
\text { [38] }\end{array}$ & Ghana & Local herbs ingested by mothers & $\begin{array}{l}\text { Prevents sunsumyare (spiritual sickness), promotes maternal, fetal } \\
\text { health, prevents complications }\end{array}$ \\
\hline $\begin{array}{l}\text { Hadwiger } \\
\text { [50] }\end{array}$ & Philippines & Ginger, carried & Protect unborn baby from aswang (evil spirits) \\
\hline $\begin{array}{l}\text { Lundberg } \\
\text { [49] }\end{array}$ & Vietnam & $\begin{array}{l}\text { Pig's trotter with papaya or red bean and potato, } \\
\text { meat and eggs }\end{array}$ & $\begin{array}{l}\text { Enrich blood, help recovery, encourage expulsion of the lochia, } \\
\text { stimulate lactation }\end{array}$ \\
\hline $\begin{array}{l}\text { Maimbola } \\
\text { [41] }\end{array}$ & Zambia & Traditional medicine applied to vagina & Prepare and widen the birth canal in pregnant women \\
\hline \multirow{2}{*}{$\begin{array}{l}\text { Ngomane } \\
\text { [83] }\end{array}$} & \multirow[t]{2}{*}{ S Africa } & Mbita, Ritlangi, Mpundulo & \multirow{2}{*}{$\begin{array}{l}\text { Strengthen and preserve pregnancy } \\
\text { Induction, management of labour and management of pain }\end{array}$} \\
\hline & & Mbheswana, roots of Xirhakarhani, boiled Dinda & \\
\hline $\begin{array}{l}\text { Radoff } \\
\text { [103] }\end{array}$ & Guatemala & $\begin{array}{l}\text { Teas and baths from grasses and trees, cypress, pine, } \\
\text { oak, pear, eucalyptus }\end{array}$ & Stimulate labour, reduce postpartum bleeding \\
\hline \multirow[t]{2}{*}{ Raven [48] } & \multirow[t]{2}{*}{ China } & Ginger and wine & \multirow{2}{*}{$\begin{array}{l}\text { Enrich blood, help recovery, encourage expulsion of the lochia, } \\
\text { stimulate lactation }\end{array}$} \\
\hline & & Meat and eggs & \\
\hline Sein [39] & Myanmar & Turmeric, ingested or applied on skin & Prevent muscle pain and to prevent newborn from abdominal pain \\
\hline Thapa [52] & Nepal & Mustard oil, turmeric, eggs ingested & Regain energy post-partum, make womb strong, relieve pain \\
\hline \multirow[t]{2}{*}{$\begin{array}{l}\text { Theroux } \\
{[58]}\end{array}$} & \multirow[t]{2}{*}{ Ghana } & $\begin{array}{l}\text { Bitter leaf, dandelion, prekos, maringa, nim tree, and } \\
\text { kontosi }\end{array}$ & Treat minor illness and maintain/improve pregnancy \\
\hline & & Fou-fou pounding & Prepare for labour \\
\hline \multirow{2}{*}{$\begin{array}{l}\text { Wulandari } \\
\text { [44] }\end{array}$} & \multirow[t]{2}{*}{ Bali } & Tamarind, turmeric, cinnamon, clove, coconut & \multirow[t]{2}{*}{ Improve maternal and infant health } \\
\hline & & Herbal medicines & \\
\hline
\end{tabular}


braised with salt, pepper, and palm sugar by women who could afford it [47]. In China, meat and eggs were regarded as "hot"; food could be made "warmer" by adding ginger and wine and "warm" food helped restore balance [48]. Vietnamese cultural practices relating to food were similar; fresh vegetables and fruits were considered 'cold', but new mothers were allowed to consume some boiled vegetables [49]. Traditionally Asian women were encouraged to eat high protein or 'hot' foods to build up the lost vital energy or chi'I [49].

In Vietnam, the most common foods encouraged to stimulate lactation were pig nails with green papaya or red bean and potato, considered helpful in increasing milk production [46]. Almost diametrically opposed was the view from Bali that "it is better if we eat lots of vegetables" because vegetables increase the production and 'freshen' the taste of breast milk [44]. In Bengal, postpartum mothers were encouraged to take milk, ghee, butter, and certain types of fish to increase the quantity of breast milk and encouraged to eat garlic believed to enhance the process of "drying of the womb" [31]. In the Philippines, boiled vegetables or laswa was promoted in pregnancy to make the mother and the foetus strong. As this quote from a young mother typifies [50]:

I eat laswa especially tugabang a slippery type green leafy vegetable that my mother and paltera

(traditional birth attendant) believes will help with easy delivery and my friends who had babies also did.

In Zambia, mothers were encouraged to eat locally defined nourishing foods, such as cooked vegetables with pounded groundnuts and nshima (maize flour) [41].

Many foods were proscribed in pregnancy, often those that were classified as 'cold'. In Pakistan, recent mothers were advised "not to eat rice, prawns and fish" since it would cause lower abdominal pain $[16,51]$. On the other hand, women were advised to eat specific types of food in order to bleed heavily since women perceived heavy post-partum bleeding as "healthy since it releases the impurities from the woman's stomach." An educated informant from urban Karachi with two children stated [51]:

Goandh (sweet made out of semolina, sugar, clarified butter and nuts) is eaten in order to bleed heavily. Also, turmeric powder, dried dates in milk and herbs help one to bleed heavily.

Most fruit and vegetables were thought to be cold; the effects of eating 'cold' food include diarrhoea in baby and mother, body swelling, stomach discomfort, aches and pains and cough [48]. South Asian women also believed that 'cold' foods, such as yogurt during the puerperium can have long-term negative health consequences including "body aches, weakness and fever" [51]. Foods considered taboo post-partum in rural Bengal were: certain varieties of green leafy vegetables, fibrous vegetables, melons, gourds, pumpkin, papaya, eggplant, shell fish, eggs, lemons, limes, oranges, grapes, chillies, bell peppers, spices, bananas, yoghurt, and oily food [31].

In Nepal, green vegetables, pumpkins and apples were considered to be cold food and believed to cause diarrhoea for the child through mother's milk, therefore restricted for two to three months after delivery [52]. Khmer women were in fact so concerned of the high risk of pit duen (emic term for post-partum sickness) which is felt to be food related, that they end up with a severely restricted diet, as many taboo foods are part of everyday diets [27]. Traditional birth attendants in Zambia advised expectant mothers not to eat eggs as "the baby will be born without hair," to avoid fish as this can "cause infant abnormality" [41]. There was little consistency in what foods were considered helpful or harmful, even within small rural populations in the same country. For example in rural Laos, some considered that eating coconut or pork would make the baby fat and cause a difficult birth; in an adjacent village, eating coconut was thought to make delivery easier [27].

\section{Restrictive practices during perinatal period influencing maternal nutrition: “They don't let you eat, you can't eat salt, oil, ...you can't eat your fill" [53]}

Restrictive practices in the perinatal period were widespread across Asia, Africa and parts of Latin America and involved food, physical activity including sexual intercourse and women's mobility. Cultural taboos related to food avoidance of 'bad' food and restriction went hand in hand and was particularly prevalent and persistent in Asia. As this quote from a mother in rural Bengal (India), restriction of both quantity and type of food was practised [31]:

After delivery for the first three days I was on a diet of dry food, such as rice crisps, garlic, and ghee, and was allowed to eat only once a day, as this diet helps to contract the uterus quickly.

Strict home confinement post-partum common in south-east Asia, was usually spent at the natal home, and could last from seven days to 41 days. The Chinese practice of zuo yuezi or 'doing the month' (although the period may stretch beyond the month) is intended for the mother to recover her physical strength after birth. While Chinese mothers were aware of the need to enhance their nutrition, during zuo yuezi food was restricted to easily digestible foods such as millet soup, 
brown sugar water and eggs [53]. Due to the severe food restrictions and lack of sunlight as women were confined to a dark room, women can grow weak over the time period, "after 40 days, I couldn't even stand up!" as one post-partum woman in rural China reported [53].

Women in Myanmar like their counterparts in China abstained from sex, avoided exposure to wind and cold, handling soap, or strenuous house hold chores. They shunned the smell of frying or burning as it could "cause puffiness of the face," avoided quarrelling, crying, reading and watching television/video [39]. For Khmer women, who have many emic terms for perinatal health/ wellbeing states, relapse from food appeared to be most common type of "toas" (post-partum state with symptoms including headache, diarrhoea, weakness, palpitations, abdominal pains or cramps, and poor appetite), leading to many prohibitions during the postpartum period. Foods considered particularly dangerous for postpartum women included pineapple, jackfruit, different varieties of bananas, field cucumbers, buffalo meat, pig's head, and different varieties of fish [40]. Bangladeshi women like their South Asian counterparts reported rigidly controlled diets after birth; they were advised to eat dry food, and rice with mashed potato and black cumin seed; to "cool women's stomachs and promote production of breast milk" [54].

In parts of Africa, there were strong restrictions on mobility, activity and food during pregnancy; the foods to be avoided often included locally available, protein and energy-rich sources. In Nigeria, the traditional healer was often the first person to 'diagnose' the pregnancy, and would proscribe various activities once pregnancy was confirmed including moving about after dark and eating a range of foods such as okra, snails, bush meat, peanuts and bananas [55]. Indigenous women from Brazil also practiced strict confinement or resguardo after childbirth with food restrictions; lasting for 40 days. Taboo foods included certain fish, monkeys, tapir, caiman, some turtles, wild pigs and numerous fruits; these make mothers faz mal [sick] [56].

\section{Cross-cutting themes}

The following themes seemed to underpin maternalinfant nutritional practices across geographical regions, reflecting society-wide aspects. There were striking similarities across studies from disparate geographical regions and settings.

Role of woman/mother/wife as strong and good: "I guess as women we just bear that burden" [53]

In many traditional societies, a woman's worth is pegged to her performance of culturally defined reproductive and productive roles. Similar to other groups for example, the Sabiny (Uganda), regarded motherhood as one of the most important attributes defining a married woman and hard work and endurance were synonymous with pregnancy and childbirth [57]. Coping with severe restrictions and bearing pain throughout the perinatal period were considered to demonstrate strength in mothers. Thus post-partum Khmer women for example would stick to a very restricted diet of salt and galangal up to one month even though some may be crying with hunger [27].

\section{Poverty and its pervasive effects on perinatal nutrition: "We mostly eat the cheapest available food" [29]}

For many childbearing women in low resource settings, knowledge of good nutrition in the perinatal period, whether culturally sanctioned or promoted by healthcare workers could not be put into practice. Ghanaian mothers admitted that although they knew the importance of vegetables, they could not afford to buy them [58], Argentinian mothers similarly knew about good perinatal nutrition, but only "when I can afford them" [59]. Pregnant Kenyan women knew what 'good' foods were, but consumed just carbohydrates as they could not afford good food regularly [45]. In rural Bengal, women who had any 'special' food, were from upper socioeconomic backgrounds and women who had delivered at their natal homes [31]. Some women simply could not "afford the cost of eating more" during the critical perinatal period [33].

\section{Change is constant but direction of change unpredictable: "But now we have forgotten our herbs because there are hospitals around" [36]}

This theme was evident in the changing breastfeeding practices in spite of strong cultural support. For example, Chinese women acknowledged the nutritional value of breast milk as it promoted "immunity in the baby; makes the uterus smaller; ..... helps the relationship between the mother and baby" [48]. Exclusive breastfeeding was however rare and supplementing common. Even in well supported programs, mothers in South Asia, reported knowing about colostrum and its benefits for babies, "but this knowledge not translated properly into practice" [60].

The studies examined displayed cultural practice being dynamic, however, as this quote from a Ghanaian woman suggests, change in cultural practice may come at a price [36]:

But now we have forgotten our herbs because there are hospitals around. Most of the herbs can't even be found today, and we don't know the laws of the herbs. The hospital is good, but most of us can't afford to go there. 
It was not unusual for pregnant or lactating mothers, supported by their families, to supplement western medicines with traditional medicines. As expressed by this Ghanaian mother, "I made sure that I took all the drugs they gave me at the clinic. ... at times, too, I prepared herbs ....and added it to the drugs" [61]. The practice of "doing the month" is also morphing slowly, now women may eat "rice porridge, noon a bowl of noodles and two eggs, maybe two slivers of vegetables.... In the past, all the mother could do was drink millet soup" [53]. Contemporary Swazi mothers might resist using traditional medicines during pregnancy because they do not believe in them; in the postpartum period however, they use traditional medicines on their babies as they surrender to the cultural authority of their in-laws [62]. Some Ghanaian women also resist traditional herbs as "I'm afraid [herbs would] abort the baby" [38].

There was evidence of positive change in breastfeeding practice although slow, "I didn't give the baby anything until the breast milk came. I just kept on putting him on the breast" (older mother, Uganda, one of small minority) [34].

\section{Discussion}

Our review and synthesis of qualitative studies exploring the perinatal period in low resource settings found that cultural influences on maternal and infant nutrition remain strong and they extend throughout the perinatal continuum. The richness and diversity of cultural practices that continue to influence perinatal nutrition both in urban and rural settings across LMICs, supports our view that generalisation is not possible and comparison between groups and regions is in fact odious. It is likely that cultural beliefs and understanding exert a stronger influence on maternal behaviour in relation to nutrition, than biomedicine. There is strong cultural support for many health promoting and life-giving nutrition practices such as breastfeeding, and the acknowledgement of the inherent healing properties of foods. Change is occurring in cultural practices and sometimes rapidly, but there is an inherent tension in incorporating 'positive' behaviour change versus resisting change. As Kaphle et al. [63], note with respect to childbirth traditions in Nepal, there is a schism between medical and cultural understanding; biomedicine needs to "understand and accommodate culture and tradition."

While we found strong cultural support and perhaps ambivalent support from elders for breastfeeding, it may no longer be seen as the norm [64]. Optimum breastfeeding is under threat globally, despite robust evidence for exclusive breastfeeding [65] and sound infant and young child feeding strategies being promoted [66]; with only a third of infants worldwide exclusively breastfed for the first four months of life [67]. We know that many upstream determinants such as poverty, livelihood and living arrangements, as well as poor social support and poor knowledge, socio-cultural factors, myths and misconceptions affect breastfeeding duration in low resource settings [68, 69]. With rapid demographic change, practices are changing and not always in the direction expected. For example in the Tsimane tribe in Bolivia, contrary to expectations breastfeeding is most intensive in the most modernized villages [70].

The range of foods considered culturally supported and 'good' versus 'bad' through the perinatal period may appear bewildering, but health professionals need to acknowledge that notions of heating and cooling foods have far more currency across Asia than bio-medically supported nutrition choices [71]. There were certainly contradictions between regions and population groups and often a lack of consistency between populations living in close proximity, about good and bad foods for mother and infant. What is worth celebrating and building on however, is the cultural acknowledgement of the healing role of local foods.

Of greatest concern for maternal and infant wellbeing, were the widespread and still current, restrictive practices curtailing women's mobility and nutrition. In fact more foods were restricted and considered taboo, than were promoted or allowed. While the origin of the postpartum confinement practices such as resguardo and zuo yuezi have their bases in restoring women's health and strength, they might conversely do the opposite. The cultural underpinning of women's role as wife, mother and reproducer and therefore needing to 'bear' suffering and hardship appear so strong as to negate the life affirming and health promoting aspects of other practices in this period. Studies in South Asia and Africa have shown that with greater access to biomedical health services and modernisation, gender-power inequalities may even increase, with women being subjected to more restrictions and control than men are [72, 73].

We found a paucity of studies from Latin America and the middle-east in this review. This may be due to restricting our literature review to studies published in English. There are far more studies being published in the current decade and the majority of studies emanate from the regions with the greatest burden in maternal and child morbidity/mortality. Nevertheless it would be worthwhile to explore whether the themes we identified have similar currency or transferability across other regions within LMIC. Our perception from the review is that there is a tendency for studies to report mainly negative (or biomedically 'frowned upon') traditional practices.

\section{Conclusions}

We believe that more attention needs to be paid to the important dimension of culture in influencing perinatal 
nutrition. There is an urgent need for more interdisciplinary research into socio-cultural factors influencing perinatal nutrition that is readily available for practitioners and policymakers. Whilst attempts to unpack the reasons behind the alarming rates of maternal and child malnutrition in South Asia and sub Saharan Africa are underway, attention needs to be paid to the role of culture in influencing not only women's choices in nutrition, but other inter-related health behaviour throughout the perinatal continuum. The gendered expectation of women's roles as reproducers and the influence of restrictions on women's mobility and access to appropriate nutrition need to be acknowledged in the context of upstream factors such as poverty. Contextually specific, culturally responsive perinatal nutrition interventions therefore are needed to optimise health and wellbeing of mother-infant dyads. Maternal and infant nutrition messages need to incorporate local understanding, such as that of 'hot' and 'cold' foods, while at the same time ensuring the promotion of nutritious, locally available foods. Public health policymakers and clinicians need to design interventions that build on culturally sanctioned life affirming behaviour such as breastfeeding, promoting post-partum rest and recovery, while modifying the harmful aspects of other perinatal cultural practices; always acknowledging the centrality of culture and understanding that 'culture is change'.

\section{Additional file}

Additional file 1: PRISMA 2009 Checklist. (DOC 63 kb)

\section{Abbreviations}

CASP, Critical Appraisal Skills Programme; COREQ, consolidated criteria for reporting qualitative research; LMIC, low and middle income countries; MDG, millennium development goal; PRISMA, preferred reporting items for systematic reviews and meta-analyses

\section{Acknowledgements}

The first author gratefully acknowledges the guidance from Dr Allison Tong in performing a systematic review and synthesis of qualitative studies. The first author also acknowledges the support from the staff of the School of Public Health \& Community Medicine, University of New South Wales.

\section{Funding}

Nil

\section{Availability of data and materials}

Not applicable, all data extracted from previously published papers, all references provided.

\section{Authors' contributions}

SR was responsible for the original research conception, project design for systematic review, literature review, synthesis, interpretation/analysis, and drafted the manuscript. RN participated in the literature search, helped with reviewing studies, synthesis and analysis. JN participated in the synthesis of qualitative data and writing up. HR participated in the synthesis of qualitative data and writing up. SS participated in the literature search and helped with reviewing studies. All authors read and approved the final manuscript.

\section{Author information}

The first author has completed a PhD in public health. She is a paediatrician and has clinical and research experience in the health of migrants and refugees, maternal, newborn and child health, indigenous child health, and violence against women and children. She has extensive experience in qualitative research methods.

\section{Competing interests}

The authors declare that they have no competing interests.

\section{Consent for publication}

Not applicable

\section{Ethics approval and consent to participate}

Not applicable as this was a synthesis of previously published studies. All included studies had an ethics statement listed in their publication.

\section{Author details}

${ }^{1}$ School of Public Health \& Community Medicine, University of New South Wales, \& South Western Sydney Local Health District, Health Services Building Level 3, Cnr Campbell \& Goulburn St, Liverpool, NSW 2170, Australia. ${ }^{2}$ Faculty of Health, University of Technology, Sydney Level 7, 235 Jones St, Ultimo, NSW 2007, Australia. ${ }^{3}$ School of Public Health \& Community Medicine, University of New South Wales, Samuels Building, Gate 11, Botany Street, Randwick, UNSW, Sydney, NSW 2052, Australia.

Received: 1 March 2016 Accepted: 23 July 2016

Published online: 28 July 2016

\section{References}

1. Lopez AD, Mathers CD, Ezzati M, Jamison DT, Murray CJL. Global and regional burden of disease and risk factors, 2001: systematic analysis of population health data. Lancet. 2006;367:1747-57.

2. Murray CJL, Vos T, Lozano R, Naghavi M, Flaxman AD, Michaud C, Ezzati M, Shibuya K, Salomon JA, Abdalla S, et al. Disability-adjusted life years (DALYS) for 291 diseases and injuries in 21 regions, 1990-2010: a systematic analysis for the Global Burden of Disease Study 2010. Lancet. 2012;380(9859):2197-223.

3. Babalola S, Fatusi A. Determinants of use of maternal health services in Nigeria - looking beyond individual and household factors. BMC Pregnancy Childbirth. 2009;9(1):43.

4. Chowdhury ME, Botlero R, Koblinsky M, Saha SK, Dieltiens G, Ronsmans C. Determinants of reduction in maternal mortality in Matlab, Bangladesh: a 30-year cohort study. Lancet. 2007;370(9595):1320-8.

5. Agha S. The determinants of infant mortality in Pakistan. Soc Sci Med. 2000; 51(2):199-208.

6. Legge D, Sanders D. Commentary: new development goals must focus on social determinants of health. BMJ. 2013; 346:f1893.

7. Mumtaz Z, Salway S, Bhatti A, Shanner L, Zaman S, Laing L, Ellison GTH. Improving maternal health in Pakistan: toward a deeper understanding of the social determinants of poor women's access to maternal health services. Am J Public Health. 2014;104(S1):S17-24.

8. Bhutta ZA, Darmstadt GL, Hasan BS, Haws RA. Community-based interventions for improving perinatal and neonatal health outcomes in developing countries: a review of the evidence. Pediatrics. 2005;115(2 Suppl):519-617.

9. Bhutta ZA, Das JK, Rizvi A, Gaffey MF, Walker N, Horton S, Webb P, Lartey A, Black RE. Evidence-based interventions for improvement of maternal and child nutrition: what can be done and at what cost? Lancet. 2013;382(9890):452-77.

10. Streatfield PK, Koehlmoos TP, Alam N, Mridha MK. Mainstreaming nutrition in maternal, newborn and child health: barriers to seeking services from existing maternal, newborn, child health programmes. Matern Child Nutr. 2008;4:237-55.

11. Bryce J, Coitinho D, Darnton-Hill I, Pelletier D, Pinstrup-Andersen P. Maternal and child undernutrition: effective action at national level. Lancet. 2008; 371(9611):510-26.

12. Ugwu NU, Kok B. Socio-cultural factors, gender roles and religious ideologies contributing to Caesarian-section refusal in Nigeria. Reprod Health. 2015;12:70 
13. Moyer C, Adongo P, Aborigo R, Hodgson A, Engmann C, DeVries R. 'It's up to the woman's people': How social factors influence facility-based delivery in rural Northern Ghana. Matern Child Health J. 2014;18(1):109-19.

14. Okolocha C, Chiwuzie J, Braimoh S, Unuigbe J, Olumeko P. Socio-cultural factors in maternal morbidity and mortality: a study of a semi-urban community in southern Nigeria. J Epidemiol Community Health. 1998;52(5):293-7.

15. Dongre AR, Deshmukh PR, Garg BS. Childhood morbidity, household practices and health care seeking for sick children in a tribal district of Maharashtra, India. Indian J Med Sci. 2010;64(1):7-16.

16. Fikree FF, Ali TS, Durocher JM, Rahbar MH. Newborn care practices in low socioeconomic settlements of Karachi, Pakistan. Soc Sci Med. 2005; 60(5):911-21.

17. Bhutta ZA, Shekar M, Ahmed T. Mainstreaming interventions in the health sector to address maternal and child undernutrition. Matern Child Nutr. 2008:4 Suppl 1:1-4.

18. Geertz C. The interpretation of cultures. New York: Basic Books; 1973.

19. Kiefer CW. Doing health anthropology: research methods for community assessment and change. New York: Springer Publishing Company; 2007.

20. Dixon-Woods M, Bonas S, Booth A, Jones DR, Miller T, Sutton AJ, Shaw RL Smith JA, Young B. How can systematic reviews incorporate qualitative research? A critical perspective. Qual Res. 2006;6(1):27-44.

21. Thomas J, Harden A. Methods for the thematic synthesis of qualitative research in systematic reviews. BMC Med Res Methodol. 2008:8:45.

22. The World Bank. Country and lending groups. Washington DC: The World Bank; 2015.

23. Liberati A, Altman DG, Tetzlaff J, Mulrow C, Gøtzsche PC, loannidis JPA, Clarke M, Devereaux PJ, Kleijnen J, Moher D. The PRISMA statement for reporting systematic reviews and meta-analyses of studies that evaluate health care interventions: explanation and elaboration. PLoS Med. 2009;6(7): e1000100.

24. Tong A, Sainsbury P, Craig J. Consolidated criteria for reporting qualitative research (COREQ): a 32-item checklist for interviews and focus groups. Int J Qual Health Care. 2007;19(6):349-57.

25. CASP. Critical Appraisal Skills Programme (CASP) qualitative research checklist. Oxford: CASP UK; 2013.

26. QSR International. In: NVivo, editor. NVivo 10 for Windows, vol. 10. Doncaster: Victoria QSR International Pty Ltd; 2015.

27. de Sa J, Bouttasing N, Sampson L, Perks C, Osrin D, Prost A. Identifying priorities to improve maternal and child nutrition among the Khmu ethnic group, Laos: a formative study. Matern Child Nutr. 2013:9(4):452-66.

28. Lee M, Durham J, Booth J, Sychareun V. A qualitative study on the breastfeeding experiences of first-time mothers in Vientiane, Lao PDR. BMC Pregnancy Childbirth. 2013;13:223

29. Dykes F, Lhussier M, Bangash S, Zaman M, Lowe N. Exploring and optimising maternal and infant nutrition in North West Pakistan. Midwifery. 2012;28(6):831-5.

30. Ergenekon-Ozelci P, Elmaci N, Ertem M, Saka G. Breastfeeding beliefs and practices among migrant mothers in slums of Diyarbakir, Turkey, 2001. Eur J Public Health. 2006;16(2):143-8.

31. Bandyopadhyay M. Impact of ritual pollution on lactation and breastfeeding practices in rural West Bengal, India. Int Breastfeed J. 2009;4:2

32. Winch PJ, Alam MA, Akther A, Afroz D, Ali NA, Ellis AA, Baqui AH, Darmstadt GL, El Arifeen S, Seraji MHR. Local understandings of vulnerability and protection during the neonatal period in Sylhet District, Bangladesh: a qualitative study. Lancet. 2005:366(9484):478-85.

33. Khadduri R, Marsh DR, Rasmussen B, Bari A, Nazir R, Darmstadt GL. Household knowledge and practices of newborn and maternal health in Haripur district, Pakistan. J Perinatol. 2008;28(3):182-7.

34. Ayiasi MR, Royen K, Verstraeten R, Atuyambe L, Criel B, Garimoi CO, Kolsteren P. Exploring the focus of prenatal information offered to pregnant mothers regarding newborn care in rural Uganda. BMC Pregnancy Childbirth. 2013;13:176

35. Orisaremi TC. The influence of breastfeeding beliefs on the sexual behavior of the Tarok in north-central Nigeria. Sex Reprod Healthc. 2013;4(4):153-60.

36. Mills S, Bertrand JT. Use of health professionals for obstetric care in Northern Ghana. Stud Fam Plann. 2005:36(1):45-56.

37. Premji S, Khowaja S, Meherali S, Forgeron R. Sociocultural influences on newborn health in the first 6 weeks of life: qualitative study in a fishing village in Karachi, Pakistan. BMC Pregnancy Childbirth. 2014;14(1):232.

38. Farnes $C$, Beckstrand RL, Callister LC. Help-seeking behaviours in childbearing women in Ghana, West Africa. Int Nurs Rev. 2011;58(4):491-7.
39. Sein KK. Beliefs and practices surrounding postpartum period among Myanmar women. Midwifery. 2013;29(11):1257-63.

40. White PM. Crossing the river: Khmer women's perceptions of pregnancy and postpartum. J Midwifery Womens Health. 2002:47(4):239-46.

41. Maimbolwa MC, Yamba B, Diwan V, Ransjö-Arvidson A-B. Cultural childbirth practices and beliefs in Zambia. J Adv Nurs. 2003:43(3):263-74.

42. Dako-Gyeke P, Aikins M, Aryeetey R, McCough L, Adongo PB. The influence of socio-cultural interpretations of pregnancy threats on health-seeking behavior among pregnant women in urban Accra, Ghana. BMC Pregnancy Childbirth. 2013;13:211.

43. Adams V, Miller S, Chertow J, Craig S, Samen A, Varner M. Having a "safe delivery": conflicting views from Tibet. Health Care Women Int 2005:26(9):821-51.

44. Wulandari LPL, Klinken Whelan A. Beliefs, attitudes and behaviours of pregnant women in Bali. Midwifery. 2011;27(6):867-71.

45. Geissler PW, Prince RJ, Levene M, Poda C, Beckerleg SE, Mutemi W, Shulman CE. Perceptions of soil-eating and anaemia among pregnant women on the Kenyan coast. Soc Sci Med. 1999;48(8):1069-79.

46. Lundberg PC, Ngoc Thu TT. Breast-feeding attitudes and practices among Vietnamese mothers in Ho Chi Minh City. Midwifery. 2012;28(2):252-7.

47. White PM. Heat, balance, humors, and ghosts: postpartum in Cambodia. Health Care Women Int. 2004;25(2):179-94.

48. Raven JH, Chen Q, Tolhurst RJ, Garner P. Traditional beliefs and practices in the postpartum period in Fujian Province, China: a qualitative study. BMC Pregnancy Childbirth. 2007;7:8.

49. Lundberg PC, Trieu Thi Ngoc T. Vietnamese women's cultural beliefs and practices related to the postpartum period. Midwifery. 2011;27(5):731-6.

50. Hadwiger MC, Hadwiger SC. Filipina mothers' perceptions about childbirth at home. Int Nurs Rev. 2012;59(1):125-31.

51. Fikree FF, Ali T, Durocher JM, Rahbar MH. Health service utilization for perceived postpartum morbidity among poor women living in Karachi. Soc Sci Med. 2004:59(4):681-94.

52. Thapa N, Chongsuvivatwong V, Geater AF, Ulstein M. High-risk childbirth practices in remote Nepal and their determinants. Women Health. 2000;31(4):83-97.

53. Strand MA, Perry J, Guo J, Zhao J, Jane C. Doing the month: rickets and post-partum convalescence in rural China. Midwifery. 2009;25(5):588-96.

54. Choudhury N, Moran AC, Alam MA, Ahsan KZ, Rashid SF, Streatfield PK. Beliefs and practices during pregnancy and childbirth in urban slums of Dhaka, Bangladesh. BMC Public Health. 2012;12:791.

55. Ejidokun 00 . Community attitudes to pregnancy, anaemia, iron and folate supplementation in urban and rural Lagos, south-western Nigeria. Midwifery. 2000;16(2):89-95.

56. Piperata BA. Forty days and forty nights: a biocultural perspective on postpartum practices in the Amazon. Soc Sci Med. 2008;67(7):1094-103.

57. Kwagala B. Birthing choices among the Sabiny of Uganda. (Special Issue: Sexual and reproductive health issues among indigenous and minority ethnic peoples in Asia, Africa and Latin America.). Cult Health Sex. 2013;15 Suppl 3:S401-14.

58. Theroux R, Klar RT, Messenger L. Working hard: women's self-care practices in Ghana. Health Care Women Int. 2013;34(8):651-73.

59. Hess CM, Maughan E. Understandings of prenatal nutrition among Argentine women. Health Care Women Int. 2012;33(2):153-67.

60. Ahmed SM, Awlad H, Khan MA, Mridha MK, Ashraful A, Nuzhat C, Tamanna S, Kaosar A, Abbas B. Using formative research to develop MNCH programme in urban slums in Bangladesh: experiences from Manoshi, BRAC. BMC Public Health. 2010;10:663.

61. Wilkinson SE, Callister LC. Giving birth: the voices of Ghanaian women. Health Care Women Int. 2010;31(3):201-20.

62. Thwala SB, Jones LK, Holroyd E. Swaziland rural maternal care: ethnography of the interface of custom and biomedicine. Int J Nurs Pract. 2011;17(1):93-101.

63. Kaphle S, Hancock H, Newman LA. Childbirth traditions and cultural perceptions of safety in Nepal: critical spaces to ensure the survival of mothers and newborns in remote mountain villages. Midwifery. 2013; 29(10):1173-81.

64. World Breastfeeding Trends Initiative (WBTi). Are our babies falling through the gaps? The state of policies and programme implementation of the global strategy for infant and young child feeding in 51 countries. In: Delhi, India: Breastfeeding Promotion Network of India (BPNI)/International Baby Food Action Network (IBFAN) Asia. 2012. 
65. Kramer M, Kakuma R. Optimal duration of exclusive breastfeeding. Cochrane Database of Systematic Reviews. 2012;(8):Art. No.: CD003517.

66. WHO. Global strategy for infant and young child feeding. Geneva: World Health Organization; 2003.

67. Lutter CK, Morrow AL. Protection, promotion, and support and global trends in breastfeeding. Adv Nutr. 2013;4:213-9.

68. Kimani-Murage EW, Wekesah F, Wanjohi M, Kyobutungi C, Ezeh AC, Musoke RN, Norris SA, Madise NJ, Griffiths P. Factors affecting actualisation of the WHO breastfeeding recommendations in urban poor settings in Kenya. Matern Child Nutr. 2015;11(3):314-32.

69. Balogun OO, Dagvadorj A, Anigo KM, Ota E, Sasaki S. Factors influencing breastfeeding exclusivity during the first 6 months of life in developing countries: a quantitative and qualitative systematic review. Matern Child Nutr. 2015;11(4):433-51.

70. Veile A, Martin M, McAllister L, Gurven M. Modernization is associated with intensive breastfeeding patterns in the Bolivian Amazon. Soc Sci Med. 2014; 100:148-58.

71. Raman S, Srinivasan K, Kurpad A, Razee H, Ritchie J. "Nothing special, everything is Maamuli": socio-cultural and family practices influencing the perinatal period in Urban India. PLoS One. 2014;9(11):e111900.

72. Mbekenga CK, Pembe AB, Darj E, Christensson K, Olsson P. Prolonged sexual abstinence after childbirth: gendered norms and perceived family health risks. Focus group discussions in a Tanzanian suburb. BMC Int Health Hum Rights. 2013;13:1.

73. Brunson J. Confronting maternal mortality, controlling birth in Nepal: the gendered politics of receiving biomedical care at birth. Soc Sci Med. 2010; 71(10):1719-27.

74. Asowa-Omorodion Fl. Women's perceptions of the complications of pregnancy and childbirth in two Esan communities, Edo State, Nigeria. Soc Sci Med. 1997;44(12):1817-24

75. Chapman RR. Endangering safe motherhood in Mozambique: prenatal care as pregnancy risk. Soc Sci Med. 2003;57(2):355-74.

76. Degefie T, Amare Y, Mulligan B. Local understandings of care during delivery and postnatal period to inform home based package of newborn care interventions in rural Ethiopia: a qualitative study. BMC Int Health Hum Rights. 2014;14(1):17.

77. Donmozoun TS, Sombie I, Meda N. What prevent women for a sustainable use of maternal care in twomedical districts of Burkina Faso? A qualitative study. Pan African Med J. 2014; 18(43).

78. Dorwie FM, Pacquiao DF. Practices of traditional birth attendants in Sierra Leone and perceptions by mothers and health professionals familiar with their care. J Transcult Nurs. 2014;25(1):33-41.

79. Gebrehiwot T, Goicolea I, Edin K, Sebastian M. Making pragmatic choices: women's experiences of delivery care in Northern Ethiopia. BMC Pregnancy Childbirth. 2012;12(1):113

80. Gross K, Mayumana I, Obrist B. 'My wife, you are supposed to have a rest now': an analysis of norms influencing men's role in prenatal care in southeastern Tanzania. Anthropol Med. 2013;20(1):98-108.

81. Kyomuhendo G. Low use of rural maternity services in Uganda: impact of women's status, traditional beliefs and limited resources. Reprod Health Matters. 2003;11(21):16-26.

82. Lori JR, Boyle JS. Cultural childbirth practices, beliefs, and traditions in postconflict Liberia. Health Care Women Int. 2011:32(6):454-73.

83. Ngomane S, Mulaudzi FM. Indigenous beliefs and practices that influence the delayed attendance of antenatal clinics by women in the Bohlabelo district in Limpopo, South Africa. Midwifery. 2012;28(1):30-8.

84. Ad P. Understanding the phenomenon of dikgaba and related health practices in pregnancy: a study among the Batswana in the rural North West Province in South Africa. Evid Based Midwifery. 2012;10(1):29-34.

85. Thwala SBPM, Jones LKP, Holroyd EP. An ethnographic account of the beliefs, values, and experiences of rural Swazi women during childbirth. Evid Based Midwifery. 2012;10(3):101-6.

86. van der Sijpt E. Hiding or hospitalising? On dilemmas of pregnancy management in East Cameroon. Anthropol Med. 2013;20(3):288-98.

87. Warren C. Care seeking for maternal health: challenges remain for poor women. (Special Issue: Maternal and newborn health.). Ethiop J Health Dev. 2010;24(Special Issue 1):100-4.

88. Zulu EM. Ethnic variations in observance and rationale for postpartum sexual abstinence in Malawi. Demography. 2001;38(4):467-79.
89. Choudhury N, Ahmed SM. Maternal care practices among the ultra poor households in rural Bangladesh: a qualitative exploratory study. BMC Pregnancy Childbirth. 2011;11:15.

90. lyengar S, lyengar K, Martines J, Dashora K, Deora K. Childbirth practices in rural Rajasthan, India: implications for neonatal health and survival. J Perinatol. 2008;28:523-30.

91. Kesterton AJ, Cleland J. Neonatal care in rural Karnataka: healthy and harmful practices, the potential for change. BMC Pregnancy Childbirth. 2009;9(20):13.

92. Moran A, Choudhury N, Uz Zaman Khan N, Ahsan Karar Z, Wahed T, Faiz Rashid S, Alam MA. Newborn care practices among slum dwellers in Dhaka, Bangladesh: a quantitative and qualitative exploratory study. BMC Pregnancy Childbirth. 2009;9(1):54.

93. Rashid SF. Kal dristi, stolen babies and 'blocked uteruses': poverty and infertility anxieties among married adolescent women living in a slum in Dhaka, Bangladesh. Anthropol Med. 2007;14(2):153-66.

94. Sharma B, Giri G, Christensson K, Ramani KV, Johansson E. The transition of childbirth practices among tribal women in Gujarat, India - a grounded theory approach. BMC Int Health Hum Rights. 2013;13(1):41.

95. Alvesson HM, Lindelow M, Khanthaphat B, Laflamme L. Changes in pregnancy and childbirth practices in remote areas in Lao PDR within two generations of women: implications for maternity services. Reprod Health Matters. 2013;21(42):203-11.

96. Graner S, Klingberg-Allvin M, le Duong Q, Krantz G, Mogren I. Pregnant women's perception on signs and symptoms during pregnancy and maternal health care in a rural low-resource setting. Acta Obstet Gynecol Scand. 2013;92(9):1094-100.

97. Kartchner R, Callister LC. Giving birth: voices of Chinese women. J Holist Nurs. 2003;21(2):100-16

98. Matsuoka S, Aiga H, Rasmey LC, Rathavy T, Okitsu A. Perceived barriers to utilization of maternal health services in rural Cambodia. Health Policy. 2010; 95(2-3):255-63.

99. Sychareun V, Hansana V, Somphet V, Xayavong S, Phengsavanh A, Popenoe R. Reasons rural Laotians choose home deliveries over delivery at health facilities: a qualitative study. BMC Pregnancy Childbirth. 2012;12:86.

100. Abushaikha L, Massah R. Perceptions of barriers to paternal presence and contribution during childbirth: an exploratory study from Syria. Birth. 2013; 40(1):61-6.

101. Khalaf I, Callister L. Cultural meanings of childbirth: Muslim women living in Jordan. J Holist Nurs. 1997;15(4):373-88.

102. Berry NS. Kaqchikel midwives, home births, and emergency obstetric referrals in Guatemala: Contextualizing the choice to stay at home. Soc Sci Med. 2006;62(8):1958-69

103. Radoff KA, Thompson LM, Bly KC, Romero C. Practices related to postpartum uterine involution in the Western Highlands of Guatemala. Midwifery. 2013; 29(3):225-32.

\section{Submit your next manuscript to BioMed Central and we will help you at every step:}

- We accept pre-submission inquiries

- Our selector tool helps you to find the most relevant journal

- We provide round the clock customer support

- Convenient online submission

- Thorough peer review

- Inclusion in PubMed and all major indexing services

- Maximum visibility for your research

Submit your manuscript at www.biomedcentral.com/submit 